\title{
Analysis and Optimization of the Propeller Shape for a Stratospheric Drone Research Platform
}

\author{
Kamil ZENOWICZ ${ }^{1}$ and Wojciech SKARKA ${ }^{2}$ \\ Silesian University of Technology, Faculty of Mechanical Engineering, Poland
}

\begin{abstract}
Fix-wings small aircraft or drones, for flight, must be equipped with a source of thrust. In most cases, it will be propulsion systems including engine and propeller that generate the necessary thrust force. Regardless of whether the system includes an electric motor, combustion, or hydrogen engine of torque moment, the most important element of the system is the propeller. It is the element responsible for generating thrust, which is the force necessary for the flight in each of its stages. The article presents all stages of the analysis and optimization of the propeller for the considered highly flexible structure stratospheric drone. Analysis, after integration with CAD software, allows for the preparation of a comprehensive generative model. The basic propeller parameters were selected on the basis of flight altitude, considered structure, flight time, flight speed, the weight of the structure, assumed location of the engine and propeller. These assumptions made it possible to conduct a preliminary analysis of loads, propeller blade pressure distribution, thrust, and the total level of vibrations. The goal of the research is to develop a methodology of designing and preliminary analysis of propeller, which can be integrated into the generative model.
\end{abstract}

Keywords. Propeller, transdisciplinary, generative model, aircraft design, stratospheric drones.

\section{Introduction}

There are many types of propulsion used in aviation. The most common drive in civil aviation, modeling, and the drone industry is a system consisting of internal combustion or electric motor and a propeller that converts rotational energy into thrust. A very big problem is the proper selection of propeller parameters for the designed aircraft structure. This is usually a long process that requires a lot of testing. This article presents the optimization of the propeller blades used in the "Twin Stratos" UAV HALE designed by SkyTech eLab in cooperation with the Silesian University of Technology. All parameters adopted for the calculations were based on the data provided by the main designer.

The performance of the designed structure depends mainly on the quality of the selected propeller and the optimization carried out. The propeller is responsible for the greatest loss of energy supplied to the drive system due to its transformation. The main assumption of the designed HALE UAV is to use two engines whose propellers will rotate counter-rotating for stability. Maneuvering will be accomplished in part by the

\footnotetext{
${ }^{1}$ Corresponding author, Mail: kamil.zenowicz@polsl.pl.

${ }^{2}$ Corresponding author, Mail: wojciech.skarka@polsl.pl.
} 
difference in engine thrust. It follows that one propeller should provide the thrust necessary for the flight of the entire designed aircraft. Another assumption is the use of a propeller with folding blades. This is the reason that the efficiency of the central part of the propeller will be reduced.

The main research problem described in the article is the optimization of the propeller blade shape, taking into account the assumptions described above. This is an unusual case due to the high flexibility of the supporting structure and, consequently, the low allowable frequency of vibrations generated by the drive system. This problem was solved with the use of mathematical sciences and fluid mechanics, with the use of motion equations, into which the assumed input data were introduced, the procedure was also introduced in the further part of the article. The obtained results constitute comparative data for further analysis. Another scientific discipline used to solve the problem is computer science, which uses modern CAD software. The last discipline is mechanics, electrical engineering, and mechatronics based on laboratory analysis carried out in a specially designed measuring platform. The results of the analyzes were compared, and the relationships between the input data, calculated values, and measured data allowed for the creation of the propeller optimization methodology. Due to the necessity to conduct a practical analysis, a design of a measuring platform was developed, the purpose of which is to conduct comparative practical tests. The results of the practical test will be compared with the results obtained by numerical analysis.

\section{Basic propeller information}

Aviation propellers are designed to convert the rotational energy of the engine shaft to the force of thrust. The thrust is the force generated by the rotating propeller, and the axis of rotation is the direction of the force. In simplified terms, it can be assumed that the propeller is a specific gear, the efficiency, and optimization of which is the problem discussed in this article. The propeller considered and optimized is the so-called slowspeed propeller, the rotational speed of which does not exceed 6000 [rpm]. It is characterized by wide, elliptical blades.[1]

The main dimension of the propeller is its radius $\mathrm{R}$. It is the diameter of the circle made at the ends of the blades. Propeller pitch H, as shown in Figure 1. This is the distance the propeller would travel in one revolution (from point 0 to point 1 ) if it could screw into the air without slip, like a bolt into a nut [2]. The actual pitch of the propeller depends on the ratio of the flight speed to the rotational speed of the propeller. When there is no propeller thrust because the speed is very high (e.g. diving) or there is no slip because the propulsion is stationary (e.g. the start of take-off), no has high efficiency of the propeller, because at

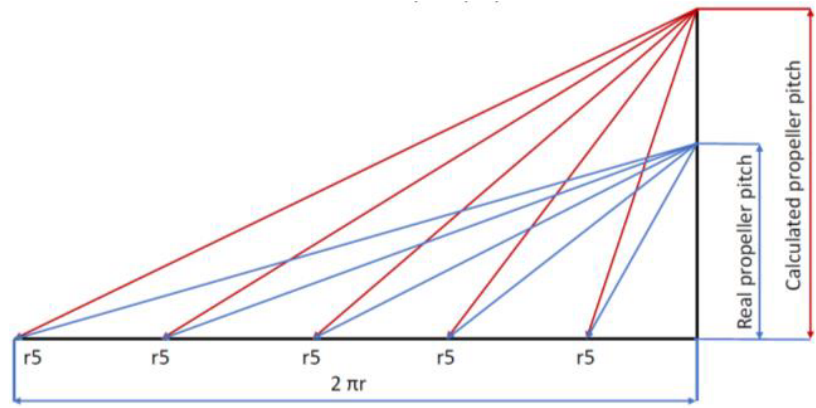

Figure 1. Fixed pitch propeller take-off it should have a small angle of attack, and as speed increases, it should increase [3]. Therefore, a fixed- 
pitch propeller achieves maximum efficiency at a certain airspeed, i.e. it is operational within a narrow speed range.

\section{Methodology of propeller optimization}

There are many ways to optimize the pitch of the propeller blades. The article presents the main methods of propeller optimization. Nowadays the most common are numerical optimization of the shape of the blades. As shown in Figure 2, this type of optimization is the easiest way to get the best results. The results are obtained using FEM analyzes that can be performed after the appropriate interference of the numerical model and, as in the case of the presented work, with the use of modern technologies enabling the production of physical elements and the analysis of their parameters for measurement platforms. Figure 3, presents the optimization process used in the analysis of the presented propeller design. Due to the time of conducting practical tests and the time of making models, the first optimization is usually performed based on the virtual environment and FEM tools. The optimization must be based on

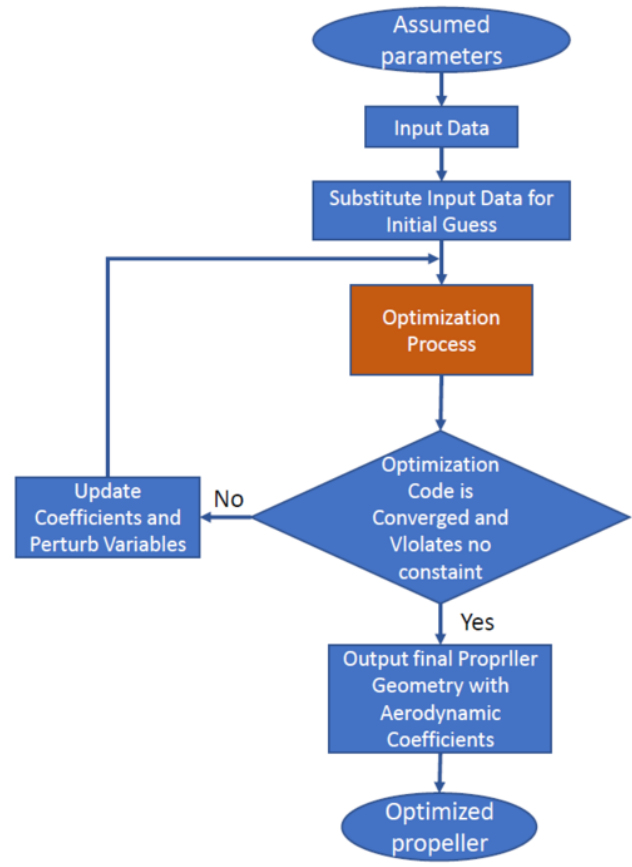

Figure 2. Propeller mathematical model optimization process chart preliminary calculations that give information about the initial diameter of the propeller, the initial position of the blade at the different radius. Table 1 shows the possible ways of analyzing the designed propeller.

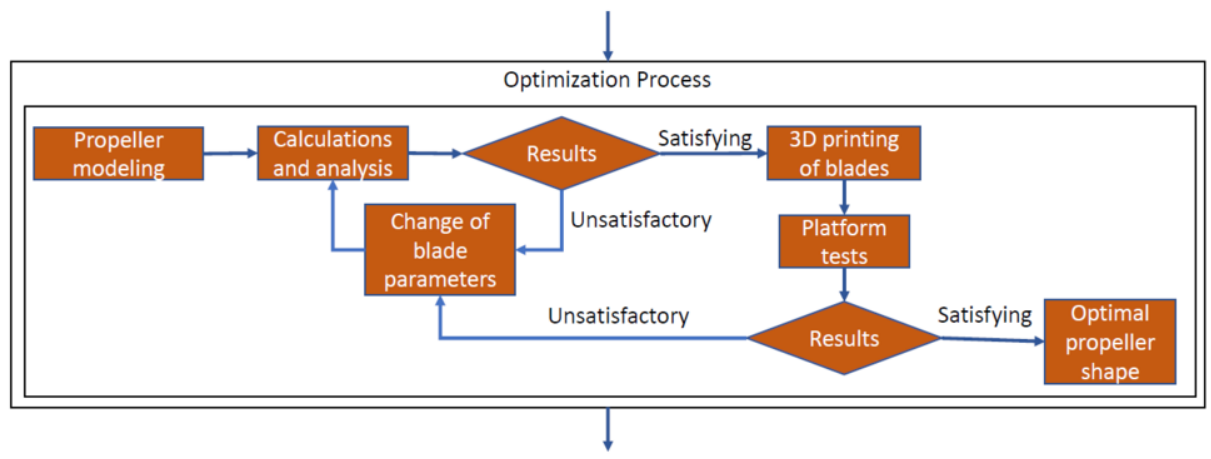

Figure 3. Propeller optimization process chart 
Table 1. Propeller optimization methods

\begin{tabular}{|c|c|}
\hline Method & Description of the method \\
\hline Empirical method & $\begin{array}{l}\text { This empirical method is based mainly on two parts namely nomographs - } \\
\text { Cluton (1990), and is a combination of graphics with lines marked with scales } \\
\text { representing parameters like power, airspeed, engine speed, propeller diameter } \\
\text { and reference lines. For design a new blade, lines are drawn (manually) } \\
\text { connecting three input parameters: engine power, engine speed and flight } \\
\text { speed. As outputs, the method provides the propeller diameter, pitch and } \\
\text { efficiency. [4] }\end{array}$ \\
\hline $\begin{array}{l}\text { Vortex Lattice } \\
\text { Method (VLM) }\end{array}$ & $\begin{array}{l}\text { To improve the efficiency of propellers using the Vortex Lattice Method, CP is } \\
\text { kept as an equality constraint and CT became an objective function. Using the } \\
\text { VLM, the twist angle distribution can be optimized. [5] }\end{array}$ \\
\hline $\begin{array}{l}\text { Chord length } \\
\text { distribution } \\
\text { optimization }\end{array}$ & $\begin{array}{l}\text { As before, CT is an objective function to be maximized and CP and AF, an } \\
\text { activity factor, are equality constraints. The activity factor is defined and it } \\
\text { represents the power absorbed by a propeller. Here, an activity factor is added } \\
\text { as another equality constraint, since the chord length distribution can be } \\
\text { optimized under the same activity factor and advance ratio. }\end{array}$ \\
\hline 3-D panel method & $\begin{array}{l}\text { The 3-D panel method used in this study is a lifting surface theory developed } \\
\text { by Cho and Williams }[7,8] \text { and it is based on unsteady, linear aerodynamics. } \\
\text { The method is brie y explained in the following subsections and more details } \\
\text { on the method can be found in [8]. }\end{array}$ \\
\hline Xrotor & $\begin{array}{l}\text { Xrotor [9] is an interactive program for the design and analysis of propellers } \\
\text { and channel and free-drive fans. Xrotor was created by Mark Drela and Hal } \\
\text { Youngren, who are also the creators of the well-known Xfoil [9]. Xrotor is } \\
\text { Fortran-based software; therefore requires the Fortran compiler to create a } \\
\text { command-line based work environment.[10] }\end{array}$ \\
\hline $\begin{array}{l}\text { CAD modeling } \\
\text { method }\end{array}$ & $\begin{array}{l}\text { Preparation for numerical optimization begins with the definition of some } \\
\text { variables and parameters that defines the problem, its possible solution domain } \\
\text { and constraints.[11] In this analysis were used SolidWorks software in which } \\
\text { optymization were made in the basis of aerodynamic thrust and moment of } \\
\text { inertia analysis results. }\end{array}$ \\
\hline
\end{tabular}

\section{Propeller appropriate profile selection for the considered aircraft}

A properly selected and optimized propeller made in the appropriate technology determines how the entire propeller will behave during take-off, flight at maximum speed, and flight with cruising speed. These parameters are best presented by a full, threedimensional Navier-Stokes solution. Unfortunately, Navier-Stokes solutions of most rotating wing devices are traditionally limited by the tendency for non-physical dissipation of vorticity and the substantial computational resource requirements [12]. There is a possibility to simulate turbulent fluid motions, Reynolds decomposed the flow quantities into its average and fluctuating components. The new quantities were substituted to the Navier-Stokes equations and as a result, Reynolds Averaged Equations (RANS) were obtained. The fluctuating components in the transport equations are unknown and cause the system of the equation not to be closed. Additional equations, which enable solving the new terms, are defined as turbulence models [13].

Based on the research carried out by Woelke [14], it can be concluded that the numerical analysis may be applicable only in the initial design stages and the physically obtained flows may have significant differences with the calculated values even when assuming the appropriate initial values and additional parameters. These differences result from parameters not included in the calculations.

The selection of the propeller is a very important element - we want to get as much thrust from the drive unit as possible. The larger the propeller, the greater the thrust, the greater the pitch for the same diameter, the greater the speed of the demonstrator. An important factor is also the type of the model under consideration - the aerobatic model 
uses propellers with a larger pitch (they fly at higher speeds), slow-rotating RC models should have a propeller with a smaller pitch (definitely slower), and models flying very slowly with the largest possible diameter for a given engine with the shortest possible stroke. Another important factor is choosing the right propeller diameter for a given engine. Too little causes the engine to run at maximum revolutions, too much overloads the engine without achieving the maximum possible thrust. The propellers with small diameter and narrow blades require very high rotational speeds - in the order of a dozen or even twenty thousand revolutions per minute, in order to generate the appropriate thrust.

Folding propellers work best in low-speed models, i.e. motor gliders. When the engine is turned on, the propeller blades unfold as a result of the centrifugal force, and when the engine is turned off - they fold along the fuselage, creating little aerodynamic drag. The motor is electrically braked, otherwise, the propeller will continue to rotate acting as a brake.

\section{Optimization based on initial calculations and aircraft parameters}

Flight parameters for the designed aircraft are a set of assumptions that allow the initial calculation of the aircraft parameters. They define the maximum flight altitude, cruising speed, or other main values. The main flight parameters necessary to do the calculations of the designed aircraft are presented in the table Table 2.

Table 2. Optimal flight parameters for propeller

\begin{tabular}{cccc}
\hline Parameter & Signature & Value & Unit \\
\hline Air speed & Va & 50 & {$[\mathrm{~km} / \mathrm{h}]$} \\
\hline Rotational speed & $\omega$ & 2100 & {$[\mathrm{rpm}]$} \\
\hline Wing area of the aircraft & $\mathrm{A}$ & 0,53 & {$[\mathrm{~m} 2]$} \\
\hline Mass of aircraft & $\mathrm{m}$ & 7,1 & {$[\mathrm{~kg}]$} \\
\hline Number of motors & $\mathrm{Nm}$ & 2 & {$[-]$} \\
\hline
\end{tabular}

A mathematical analysis was performed based on the existing propeller data based on the CLARK-Y profile. The equations presented by Romander [12] were used, these are the basic calculations used in the design of the propeller blades. This allowed for the initial determination of the value of the propeller size, generated thrust at a given flight speed and efficiency. Those parameters are presented in Table 3.

Table 3. Initial parameters of propeller.

\begin{tabular}{cccc}
\hline Parameter & Signature & Value & Unit \\
\hline Tip diameter & D & 0,37 & {$[\mathrm{~m}]$} \\
\hline Number of blades & NB & 2 & {$[-]$} \\
\hline Disc Area Ratio & DAR & 0,10752 & {$[\mathrm{~m} 2]$} \\
\hline Hub Diameter & HD & 5 & {$[\mathrm{~mm}]$} \\
\hline Hub Area & HA & 19,635 & {$[\mathrm{~mm} 2]$} \\
\hline
\end{tabular}

Obtaining these data allowed to analyze the potential linear displacement of the propeller

assuming perfect incompressibility of the surrounding center, i.e. the theoretical pitch. After taking into account the efficiency from CAD analysis of the propeller, this parameter allows determining the actual thrust.

Table 4. Calculated blade angles

\begin{tabular}{ccccc}
\hline Station & $\begin{array}{c}\text { Radius } \\
{[\mathbf{m m}]}\end{array}$ & $\begin{array}{c}\text { Pitch } \\
{[\mathbf{m m}]}\end{array}$ & $\begin{array}{c}\text { Blade } \\
\text { Angle }\end{array}$ & $\begin{array}{c}\text { Mach } \\
\text { number }\end{array}$ \\
\hline 1 & 5 & 174.68 & 79.80 & 0.017 \\
\hline
\end{tabular}

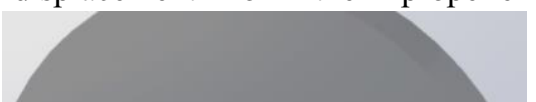

Figure 4. Standard propeller for RC airplane models 


\begin{tabular}{ccccc}
\hline 2 & 15 & 165.23 & 60.30 & 0.019 \\
\hline 3 & 25 & 164.37 & 46.30 & 0.023 \\
\hline 4 & 35 & 164.64 & 36.82 & 0.028 \\
\hline 5 & 45 & 165.28 & 30.31 & 0.033 \\
\hline 6 & 55 & 166.09 & 25.67 & 0.039 \\
\hline 7 & 65 & 166.98 & 22.24 & 0.045 \\
\hline 8 & 75 & 167.93 & 19.61 & 0.051 \\
\hline 9 & 85 & 168.91 & 17.55 & 0.057 \\
\hline 10 & 95 & 169.92 & 15.89 & 0.063 \\
\hline 11 & 105 & 170.93 & 14.53 & 0.069 \\
\hline 12 & 115 & 171.96 & 13.39 & 0.075 \\
\hline 13 & 125 & 173.00 & 12.42 & 0.082 \\
\hline 14 & 135 & 174.04 & 11.60 & 0.088 \\
\hline 15 & 145 & 175.09 & 10.88 & 0.094 \\
\hline 16 & 155 & 176.14 & 10.25 & 0.101 \\
\hline 17 & 165 & 177.19 & 9.70 & 0.107 \\
\hline 18 & 175 & 178.25 & 9.21 & 0.113 \\
\hline
\end{tabular}

Pitch p, is the theoretical axial displacement in one turn as if a reference blad section was moving without any slip Table 4, shows the initial calculations of the propeller blade and on the basis of that calculations, the first model of the propeller was designed and analyzed in CAD tool.

\section{Optimization based on an detailed virtual 3D model}

Analysis of generated thrust for two types of propellers was performed using the SolidWorks software. For this purpose, a standard propeller was used, used in modeling as a drive for model aircraft. The visualization of the analyzed propeller is presented in Figure 4. This propeller was treated as a reference point for the designed and optimized propellers.

A propeller was designed, the diameter of which did not exceed the value previously calculated based on the power method. The optimization aim to obtain the thrust necessary for flight at the maximum allowable engine speed. This parameter was obtained by changing two parameters influencing its value. These are the propeller pitch and the length of the profile chord on different propeller diameters. The main limitations are the diameter of the propeller and the amount of drag generated by the propeller. Due to the use of two propellers, the diameter must be selected in such a way as not to cause mutual losses in the thrust value. The resistance of the rotating propeller, however, cannot be too high for the previously selected electric motor.

The optimization was based on previously calculated angles of attack of the propeller in profiles on individual cross-sectional diameters. The results of the first propeller made in this way did not meet the design requirements due to the insufficient value of the thrust generated at the key rotational speeds for the designed structure. Results are presented in Table 6.

The SolidWorks FEM analysis required the creation of a virtual wind tunnel, the internal conditions of which will be strictly defined and constant. Thanks to this procedure, it was ensured that all changes in speed, pressure, and temperature were caused by the rotating tested propeller [15]. This wind tunnel is shown in Figure 5.

The figures below show the research based on of which the optimization of the blade shape, the angles of attack of individual sections, and the length of the chords used in these sections was carried out. Figures in table Table 5, show views of the air flowing while the engine is running. This

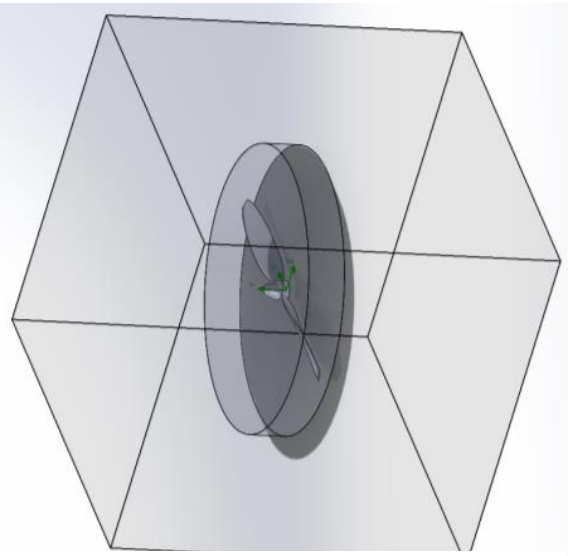

Figure 5. Virtual wind tunel with designed propeller inside 
is important because it is easy to see where and at what rotational speed the airflow starts to become unstable (turbulent).

Table5. Pressure and flow distribution during CAD analysis
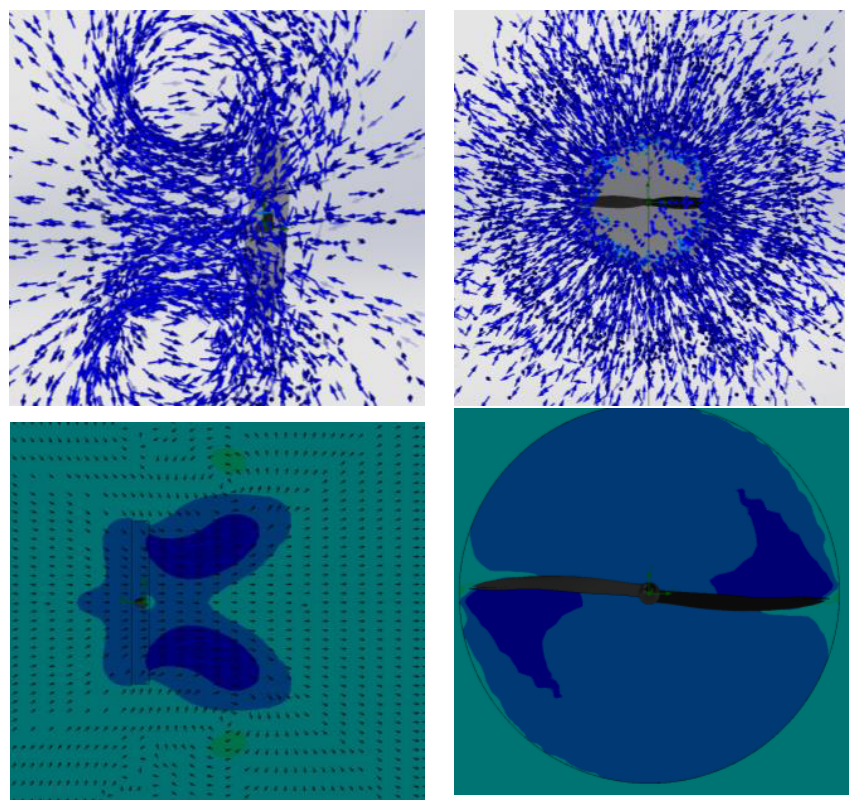

Turbulent airflow changes the performance of the propeller in the area where it occurs. The pressure changes generated by the rotating propeller shown in Table 5, define the places where the air stream hitting the wing would have a destructive effect on the aircraft, causing the vibrations in the structure. Results of analyzing the optimized type of propeller are presented in table Table 6.

Table 6. Analysis results for propeller design

\begin{tabular}{cccccc}
\hline Data & $\begin{array}{c}\text { Standard drone } \\
\text { propeller 15” }\end{array}$ & $\begin{array}{c}\text { Manually } \\
\text { calculated } \\
\text { propeller } \\
\text { first design }\end{array}$ & $\begin{array}{c}\text { SolidWorks first } \\
\text { optymized } \\
\text { propeller }\end{array}$ & $\begin{array}{c}\text { SolidWork } \\
\text { s final } \\
\text { optymized } \\
\text { propeller }\end{array}$ & Units \\
\hline Propeller design & Ready model & Design I & Design II & Design III & {$[\mathrm{mm}]$} \\
\hline Diameter of propeller & $\sim 332$ & 330 & 330 & 330 & {$[\mathrm{~N}]$} \\
\hline $\begin{array}{c}\text { Average thrust for } 100 \\
\text { [rad/s] }\end{array}$ & 0,217 & 0,291 & 0,387 & 0,337 & {$[\mathrm{~N}]$} \\
\hline $\begin{array}{c}\text { Average thrust for } 140 \\
{[\mathrm{rad} / \mathrm{s}]}\end{array}$ & 0,388 & 0,597 & 0,753 & 1,211 & {$[\mathrm{~N}]$} \\
\hline $\begin{array}{c}\text { Average thrust for } 180 \\
{[\mathrm{rad} / \mathrm{s}]}\end{array}$ & 0,703 & 0,984 & 1,275 & 1,792 & {$[\mathrm{~N}]$} \\
\hline $\begin{array}{c}\text { Average thrust for } 220 \\
{[\mathrm{rad} / \mathrm{s}]}\end{array}$ & 1,061 & 1,509 & 1,816 & 2,568 & {$[\mathrm{~N}]$} \\
\hline $\begin{array}{c}\text { Average thrust for } 260 \\
{[\mathrm{rad} / \mathrm{s}]}\end{array}$ & 1,464 & 1,978 & 2,723 & 3,296 & {$[\mathrm{~N}]$} \\
\hline $\begin{array}{c}\text { Average thrust for } 300 \\
{[\mathrm{rad} / \mathrm{s}]}\end{array}$ & 1,964 & 2,817 & 3,559 & & \\
\hline
\end{tabular}


As a result of the research, the shape of the propeller was created, which was selected to make a prototype in the form of a $3 \mathrm{D}$ printout. The model of a specific propeller will be rebuilt so that it is possible to fold the propeller. This is one of the main assumptions of the project and the work related to it will be presented in the next scientific publication. The final shape of the designed propeller is shown in Figure 6.

Due to the limitations imposed by the achievable engine power and optimal rotational speeds. The profile that generated the highest thrust was not selected as the optimal shape. The optimal profile was defined as the generated thrust was the highest for the resistance to rotation.

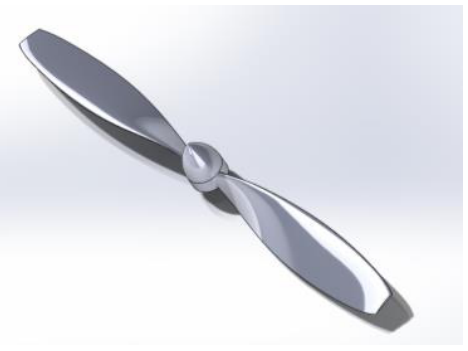

Figure 6. Final optymized propeller blade shape

\section{Presentation of the design of measuring system}

To analyze the obtained results in laboratory conditions, a measuring platform was constructed and built to measure the thrust value of the drive set in the form of an electric motor and a propeller. See Figure 7. The platform was equipped with a trolley attached to a strain gauge beam measuring the pressure force, the other end of which was attached to the mainframe of the test platform. The motor mount and the motor itself are placed on the trolley. See Figure 8. The generated thrust will be measured by a change of electrical resistance generated by the deformation of potentiometric beam. See Figure 9.

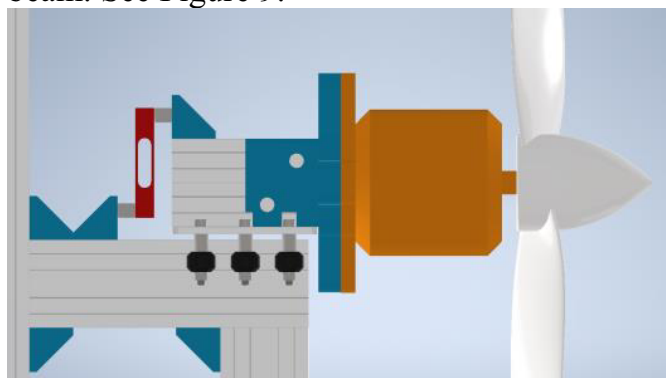

Figure 8. View of motor and propeler month in measuring system

measurement obtained from the strain gauge beam combined with the engine rotational speeds will allow generating thrust diagrams, which will be a comparative value for each of the considered propellers.

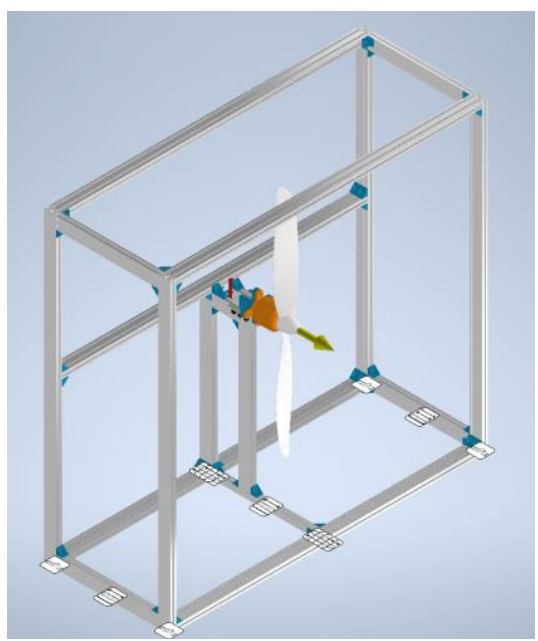

Figure 7. View of measuring system frame

Carrying out the test requires placing a linearly movable trolley on which an electric motor equipped with a speed controller will be mounted. It will allow determining the actual rotational speed of the propeller. The

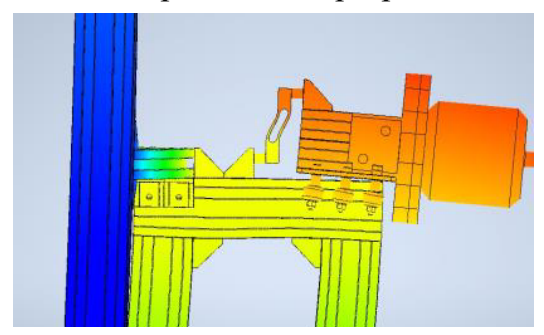

Figure 9. View of displacement during measurement 


\section{Discussion and conclusions}

Parameters based on which the preliminary calculations were made, the calculation of the necessary engine power, and the optimal propeller size and rotational speed were used to make preliminary calculations for the propeller. It should be noted that the calculations were made based on the demonstrator on a smaller scale. This model has been optimized for a specific type of mission.

Pre-determined mathematically optimal propeller sizes, mean chords and angles of attack at different reference diameters were used to generate a preliminary CAD model using SolidWorks. In this program, the first analysis of the thrust generated by the mathematically calculated propeller was also performed. The results of the analysis showed suboptimal thrust values and a significant amount of power necessary to turn the propeller.

The first shape optimization was carried out by operating the angle and chord lengths for individual reference diameters of the propeller. Many types of propellers were created and were subjected to the same virtual aerodynamic tests as the initial propeller. As a result of this test, a propeller was selected, the parameters of which correspond to the required engine rotational speed and the predetermined diameter.

The next stage of work was to develop a methodology for testing propellers that will allow determining the thrust of the analyzed propellers. In order to develop this methodology, a measuring platform has been designed on which the necessary thrust tests will be carried out. The final stage of the works will be the transformation of the developed propeller into a folded propeller. Another optimization of the blade shape for the folded propeller. Printout of optimized propeller blades and their assembly on the head with the possibility of folding the blades. Tests carried out on an estimated stand will confirm the effectiveness of the methodology for developing foldable propellers for low-speed propulsion systems of HALE UAV aircraft.

The experience gained during the analysis for the given demonstrator, based on which the above article was written, will allow for easier determination of thrust parameters, rotational speeds, and assumed propeller profiles for the TwinStratos aircraft in the 1:1 scale. The data on the calculations used for the propeller was also used to create a calculation methodology and analysis for similar HALE UAV aircraft.

\section{Acknowledgement}

We wanted to express gratitude for SkyTech eLab company for providing documentation of the Twin Stratos UAV project for research purposes.

Co-financed by the European Union through the European Social Fund (grant POWR.03.05.00-00-Z305).

\section{References}

[1] P. Yu, J. Peng, J. Bai, X. Han, X. Song, Aeroacoustic and aerodynamic optimization of propeller blades. Chinese Journal of Aeronautics, 2020, Vol. 33, pp. 826-839.

[2] M. Rostami, A. Farajollahi. Aerodynamic performance of mutual interaction tandem propellers with ducted UAV, Aerospace Science and Technology, 2021, Vol. 108, 106399.

[3] K. Wang, Z. Zhou, X. Zhu, Z. Xu, Aerodynamic design of multi-propeller/wing integration at low Reynolds numbers, Aerospace Science and Technology, 2019, Vol. 84, pp. 1-17. 
[4] O. de Almeida, F.C. de Miranda, O.F. Neto, A Comparative Study for Propeller Blade Design, Engenharia Térmica (Thermal Engineering), 2016, Vol. 15, pp. 30-37.

[5] J. Cho, S. Lee, Propeller Blade Shape Optimization for Efficiency Improvement, Computers \& Fluids, 1998, Vol. 27, pp. 407-419,

[6] R.S.A. Turner, Design and Optimisation of a Propeller for a Micro Air Vehicle Using Computational Fluid Dynamics, OFFCDT, School of Engineering \& Information Technology. ZEIT 4500 Aeronautical Thesis \& Practical Experience, Final Thesis Report 2010

[7] J. Cho and M.H. Williams, Propeller-wing interaction using a frequency domain panel method, Journal of Aircraft, 1990, Vol. 27(3), pp. 196-203.

[8] M.H. Williams, An unsteady lifting surface theory for single rotation propellers, Purdue University Report, W. Lafayette, IN, 1985.

[9] M. Drela, Xfoil: An interactive program for the design and analysis of subsonic isolated airfoils, http: //web.mit.edu/drela/Public/web/xfoil/. Accessed Februar, 2016.

[10] P. C. Klein, Parametric modeling and optimization of advanced propellers for next-generation aircraft, Delft University of Technology, Thursday August 31, 2017

[11] M. Lis, Numerical analysis and optimization of motoglider's propeller structure, Institute of aviation, al. Krakowska 110/114, 02-256 Warsaw, Poland

[12] E.A. Romander and M. Field, Computational simulation of propellers in cruise, Proceedings of the 23rd Congress of International Council of the aeronautical Sciences, Toronto, 2002, Canada, pp.212.1-212.10.

[13] Woelke, M., Viscosity turbulence Models employed by Computational Fluid Dynamic, Transactions of the Institute of Aviation, 2007, 191, pp. 92-113.

[14] K.Szafran, O. Shcherbonos, and D. Jemocki, Effects of Duct Shape on Ducted Propeller thrust Performance, Transactions of the Institute of aviation, 2014, 237, pp. 84-91.

[15] Solid Works aerodynamic analysis tutorial from: https://www.engineersrule.com/tutorial-performingflow-simulation-aerofoil/, 2021. 